\title{
Reinterventions after damage control surgery
}

\section{Reintervención en cirugía de control de daños}

OPEN ACCESS

Citation: Mejía D, Pereira WS, Delgado-López CA, Salcedo A, Rodríguez-Holguín F. Serna JJ, Salceso Y, Rojas PLF, GonzálezHadad A, Herrera MA, García A, Parra MW,Ordoñez CA. Reinterventions after damage control surgery. Colomb Méd (Cali), 2021; 52(2):e4054805 http://doi. org/10.25100/cm.v52i 2.4805

Received : 31 Mar 2021

Revised: 11 Jun 2021

Accepted : 29 Jun 2021

Published: 30 Jun 2021

Keywords:

Laparotomy, ostomy, thoracic cavity, anastomosis surgical, postoperative period, cardiac surgical procedures, intensive care units, surgical wound infection, colostomy, abdominal wall, reoperation, intra-abdominal hypertension

Palabras clave:

Laparotomía, ostomía, cavidad torácica, anastomosis quirúrgica, período postoperatorio, procedimientos quirúrgicos cardíacos, unidades de cuidados intensivos, infección de la herida quirúrgica, colostomía, pared abdominal, reoperación, hipertensión intraabdominal

\author{
David Mejia ${ }^{1,2}$ Salin Pereira Warr ${ }^{3}$ Carlos Andrés Delgado-López ${ }^{2}$ (D) Alexander \\ Salcedo ${ }^{4,5,6,7}$ Fernando Rodríguez-Holguín4 (D) José Julián Serna ${ }^{4,5,6,7}$ (D) Yaset Caicedo ${ }^{8}$ \\ (D) Luis Fernando Pino ${ }^{5,7}$ Adolfo González-Hadad5,7,9 (D) Mario Alain Herrera ${ }^{5,7}$ Alberto \\ García $^{4,5,6}$ Michael W. Parra ${ }^{10}$ Carlos A. Ordoñez ${ }^{4,5,6}$ (D) \\ ordonezcarlosa@gmail.com, carlos.ordonez@fvl.org.co
}

1 Hospital Pablo Tobon Uribe, Department of Surgery, Medellin, Colombia., 2 Universidad de Antioquia, Department of Surgery, Medellin, Colombia. 3 Hospital Pablo Tobón Uribe, Grupo de Soporte Nutricional y Pared Abdominal, Medellin. Colombia, 4 Fundación Valle del Lili, Department of Surgery, Division of Trauma and Acute Care Surgery, Cali, Colombia., 5 Universidad del Valle, Facultad de Salud, Escuela de Medicina Department of Surgery, Division of Trauma and Acute Care Surgery, Cali, Colombia., 6 Universidad Icesi, Cali, Colombia. , 7 Hospital Universitario del Valle, Department of Surgery, Division of Trauma and Acute Care Surgery, Cali, Colombia., 8 Fundación Valle del Lili, Centro de Investigaciones Clínicas (CIC), Cali, Colombia, 9 Centro Médico Imbanaco, Cali, Colombia. , 10 Broward General Level I Trauma Center, Department of Trauma Critical Care, Fort Lauderdale, FL - USA,

\section{Abstract}

Damage control has well-defined steps. However, there are still controversies regarding whom, when, and how re-interventions should be performed. This article summarizes the Trauma and Emergency Surgery Group (CTE) Cali-Colombia recommendations about the specific situations concerning second interventions of patients undergoing damage control surgery. We suggest packing as the preferred bleeding control strategy, followed by unpacking within the next 48-72 hours. In addition, a deferred anastomosis is recommended for correction of intestinal lesions, and patients treated with vascular shunts should be re-intervened within 24 hours for definitive management. Furthermore, abdominal or thoracic wall closure should be attempted within eight days. These strategies aim to decrease complications, morbidity, and mortality.

\section{Resumen}

El control de daños es uno de los pilares de la cirugía de trauma. Sin embargo, la reintervención aún genera controversias en cuanto a quién, cuándo y cómo debe realizarse. El presente artículo presenta las recomendaciones del grupo de Cirugía de Trauma y Emergencias (CTE) de Cali, Colombia, respecto a las reintervenciones después de una cirugía de control de daños. Se recomienda el empaquetamiento como la estrategia de control de sangrado y se debe desempaquetar en un lapso entre 48 y 72 horas. La anastomosis diferida debe ser la opción de reparo en las lesiones intestinales. La reintervención vascular en los pacientes manejados con shunt vascular debe ser antes de las 24 horas para dar el manejo definitivo. En un lapso de 8 días se debe intentar realizar el cierre de la pared abdominal o torácica. Estas estrategias buscan disminuir la frecuencia de complicaciones y de morbimortalidad. 
Copyright: @ $\odot 2021$ Universidad del Valle

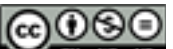

\section{Conflicts of interest:}

The authors declare that they have no conflict of interest.

\section{Acknowledgments:}

We acknowledge to Linda M. Gallego for your contributions in the drafting of this manuscript

\section{Corresponding author:}

Carlos A. Ordonez, MD, FACS. Division of Trauma and Acute Care Surgery, Department of Surgery. Fundación Valle del Lili. Cali, Colombia; Division of Trauma and Acute Care Surgery, Department of Surgery, Universidad del Valle, Cali, Colombia; Universidad Icesi, Cali, Colombia. Email: ordonezcarlosa@gmail.com, carlos.ordonez@fvl.org.co

\section{Remark}

\section{1) Why was this study conducted?}

This article summarizes the recommendations of the Trauma and Emergency Surgery Group (CTE) Cali-Colombia about the specific situations concerning re-interventions of patients undergoing damage control surgery.

\section{2) What were the most relevant results of the study?}

We suggest packing as the preferred bleeding control strategy, followed by unpacking within the following 48-72 hours. In addition, a deferred anastomosis is recommended for management of intestinal injuries, and patients managed with vascular shunts should be re-intervened within the first 24 hours for definitive repair. Furthermore, abdominal and/or thoracic wall closure should be attempted within the first 8 days upon admission.

\section{3) What do these results contribute?}

These strategies aim to decrease the overall complication, morbidity, and mortality of these patients.

\section{Introduction}

Rotondo and Schwab first described damage control surgery in 1993 and has become one of the most important advances in trauma surgery. Damage Control Surgery has impacted the morbidity and mortality of patients with major physiological impairment ${ }^{1}$. This strategy is based on an abbreviated laparotomy with abdominal packing, which allows deferring definitive surgical management until the stabilization of physiological and hemodynamic parameters ${ }^{2}$. Damage control surgery comprises a diverse spectrum of procedures such as intestinal discontinuity, solid organ packing, retroperitoneal packing, vascular shunts, and the open abdomen. All of these are temporary measures performed in response to a severe injury and metabolic debt, which requires an aggressive hemostatic resuscitation, deferred definitive management until an optimal physiological status is achieved ${ }^{3}$.

When damage control measures have been completed; the next step is to establish the time and strategy for performing the next interventions ${ }^{4}$. This decision is led by the evolution of physiological status and the severity of the injuries. However, it is accepted that to reduce morbidity and mortality rates, all definitive procedures such as intestinal/vascular reconstruction or abdominal/thoracic wall closure should be performed only when the diamond is lethal (metabolic acidosis, hypothermia, hypocalcemia, and coagulopathy) is corrected ${ }^{5,6}$. This article summarizes key recommendations concerning the most relevant controversies in surgical re-intervention during damage control surgery such as unpacking, time-lapse for intestinal anastomosis, ostomy requirement, shunt removal time, vascular reconstruction, and strategy for definitive closure of the abdomen.

This article is a consensus that synthesizes the experience earned during the past 30 years in trauma critical care management of the severely injured patient from the Trauma and Emergency Surgery Group (CTE) of Cali, Colombia which is made up of experts from the University Hospital Fundación del Valle "Evaristo García", the University Hospital Valle del Lili, the Universidad del Valle and Universidad Icesi, the Asociación Colombiana de Cirugia, the Pan-American Trauma Society and the collaboration of national and international specialists of the United States of America. 


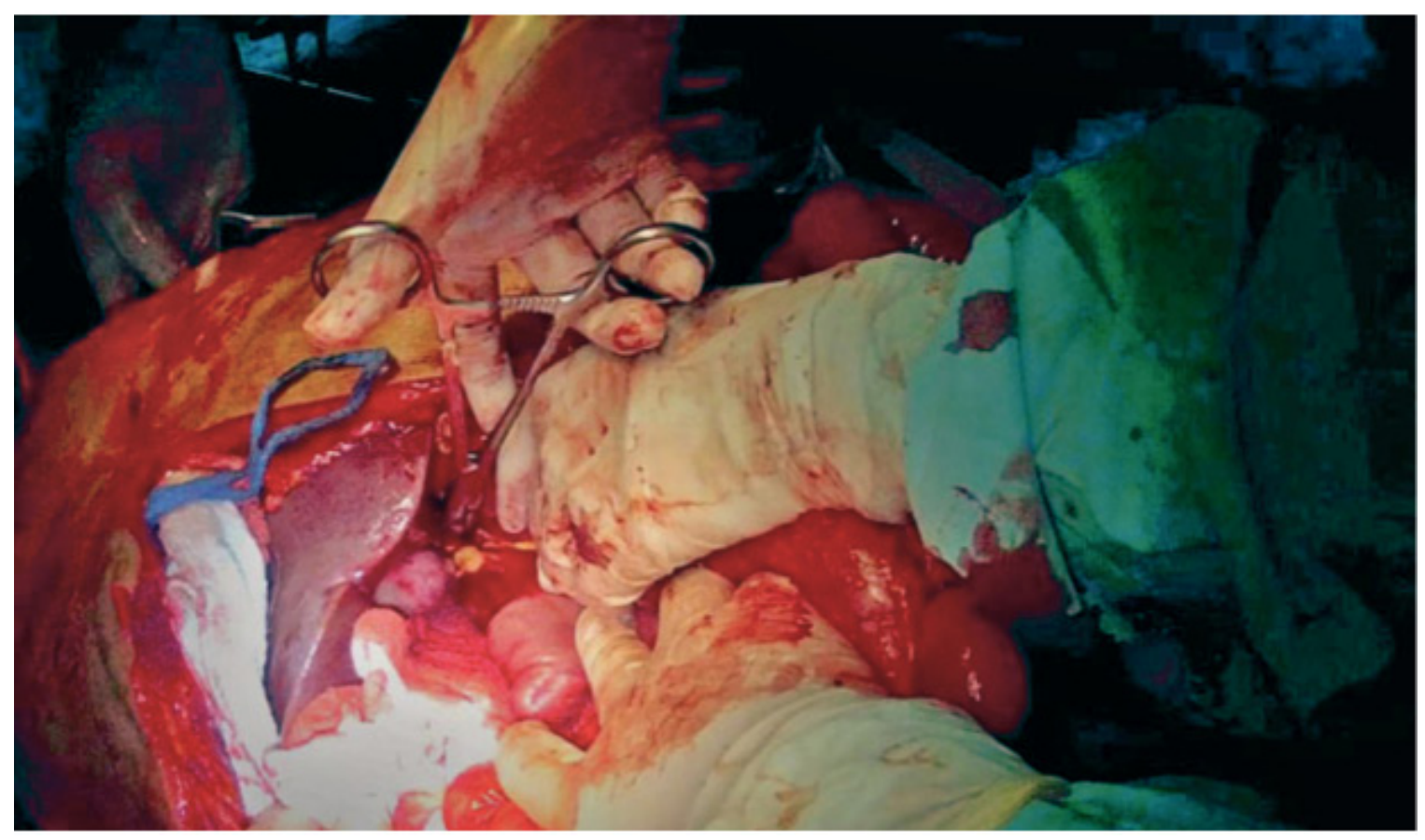

Figure 1. Abdominal Packing. Patient with a severe liver trauma that had been controlled via perihepatic packing to control of hemorrhage.

\section{Packing in damage control surgery}

Cavity or organ packing is a widely used strategy to rapidly achieve hemorrhage control during the initial phase of damage control surgery. It is usually performed when massive bleeding is found secondary to severe organ destruction, where time is limited. Packing aims to temporarily or permanently stop the bleeding by applying sustained pressure with either gauze or compresses, which results in more than $90 \%$ efficacy ${ }^{7}$. While indications for abdominal packing seem to be clearly defined, the optimal time to remove all packed material (gauze, compresses, or hemostatic agents) remains uncertain; most articles have reported a time range between 24-72 hours ${ }^{8-11}$ (Figure 1).

Aydin et al. described the use of abdominal packing in patients with severe liver trauma. Patients who were re-operated within the first 24 hours of trauma had ineffective packing (misplacement, excess or insufficient compresses) and required a longer stay in the intensive care unit and a higher transfusion of blood products ${ }^{12}$. Nicol et al. obtained similar results when they compared patients who were intervened within the first 24 hours vs. those who intervened in 48 hours. They described a higher re-bleeding rate in the first group but no differences in the infectious complications between groups ${ }^{13}$. Ordóñez et al. describe that premature packing removal increases the risk of re-bleeding while prolonging packing for more than 72 hours increases infectious complications ${ }^{7}$. Kang et al. compared patients with high-grade liver trauma who underwent unpacking before and after 48 hours. They found significantly lower ventilator-associated pneumonia rates and shorter mechanical ventilation time when unpacking was performed in the first 48 hours. However, this group had a higher hemocomponent transfusion and non-invasive procedures such as arteriography/embolization ${ }^{14}$.

Thoracic cavity packing has been initially described as a bleeding control strategy in cardiac surgery, pulmonary resection, or pleurectomy ${ }^{15-18}$. The chest cavity packing is one of the most commonly used techniques for controlling bleeding from injured surfaces, repaired tissue area, or associated with coagulopathy. ${ }^{19}$. Moriwaki et al. showed that packing had been successfully used in severe bleeding from the chest wall, paravertebral space, lung parenchyma, and bet- 
ween the chest wall and diaphragm. In this cohort, only half of the patients developed packingrelated reversible effects on ventilation or oxygenation. Unpacking was performed between the second and third day, with no procedure-related infectious complications ${ }^{20}$. In 2019, Garcia et al. described the wound tract packing in transfixing injuries of the lung parenchyma as a damage control technique, which rapidly and safely controlled the hemorrhage in all patients $(\mathrm{n}=4)$. They also recommended packing removal within the next 24-48 hours ${ }^{21}$.

Pelvic packing is one of the first-line strategies for hemorrhage control in patients with pelvic fractures and hemodynamic instability. In these patients, unpacking is recommended in the next $24-48$ hours ${ }^{22,23}$.

In conclusion, cavity or organ solid packing should not be removed before 48 hours or after 72 hours. However, in severe liver trauma, the evidence supports unpacking before 48 hours as long as it is performed along with arteriography/embolization techniques and optimal blood products transfusion ${ }^{14}$.

\section{Postoperative care and deferred intestinal anastomosis}

If fecal contamination of the peritoneum was identified during the surgical exploration, a therapeutic antibiotic scheme covering both aerobic and anaerobic microorganisms should be indicated. In contrast, if the lesion shows no signs of contamination, only a preoperative prophylactic dose of antibiotics is required.

If intestinal surgery has been performed, it is recommended to place a nasogastric tube, which has a decompressive effect on the bowel and can be used for enteral nutrition in the postoperative period, if needed.

\section{Intestinal anastomosis}

Deferred intestinal anastomosis to reduce surgical times and leakage risk has belonged to damage control surgery procedures. Left abdomen in discontinuity is to prevent further peritoneal contamination, allowing a delayed reconstruction of the gastrointestinal tract after physiological derangement has been corrected (Figure 2).

The underlying questions are: when is the optimal time to perform bowel repair and/or anastomosis? Moreover, whether or not an ostomy is required? is it necessary or not to perform an ostomy? Dysfunction of the gastrointestinal tract is the potential mechanism leading to bacte-
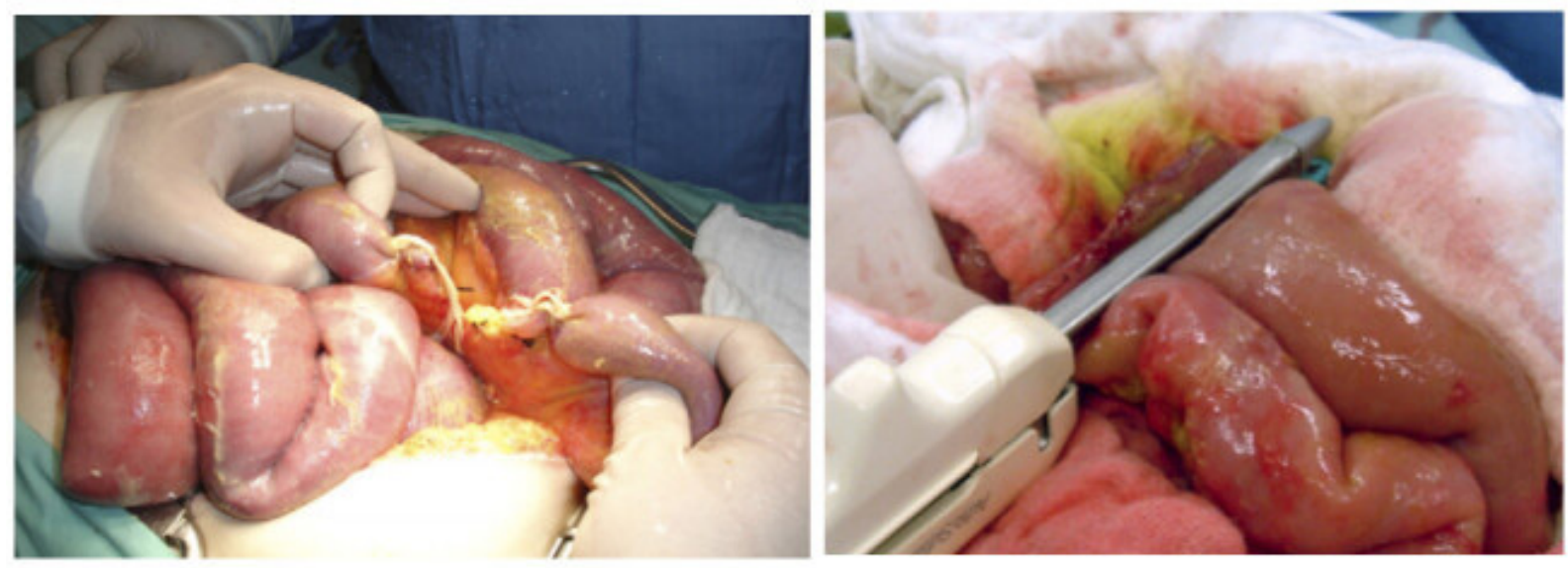

Figure 2. Deferred Intestinal Anastomosis. A. Small bowel injury is left in discontinuity as damage control surgery. B. Intestinal reconstruction via deferred small bowel anastomosis using stapple technique. 
rial translocation and sepsis. Therefore, it might complicate the prognosis of the patient in the midterm. Weinberg et al. assessed this concern by comparing patients with destructive colonic injuries who underwent definitive management in the first surgery (resection-anastomosis or resection-ostomy) with those who underwent damage control surgery with a deferred anastomosis. They found that a deferred anastomosis was associated with a higher probability of presenting colon-related complications (leakage, abscess formation, and stoma ischemia). This study also described that patients undergoing damage control surgery had a higher trauma severity and that open abdomen was managed with a negative pressure system only in $16 \%$ of the cases. Therefore, they recommended management with colostomy in a second surgical time ${ }^{24}$.

However, deferred management of destructive or multiple bowel injuries is safe and can be successfully achieved by anastomosis repair, reducing ostomy requirements and the associated morbidity and sequelae ${ }^{11,25}$. Furthermore, other studies have reported that complications such as leakage, enterocutaneous fistula, or surgical site infection do not have a frequency higher if the patient underwent definitive or abbreviated management ${ }^{9,26}$. In addition, there is not a difference regarding complications rate between patients undergoing deferred anastomosis or deferred diversion ${ }^{11,27,28}$.

The literature suggests that primary anastomosis or deferred anastomosis is safe and significantly reduces the rate of unnecessary ostomies, with no differences in complication rates compared to other procedures. A methodical analysis of the patient's physiological conditions and local variables should be performed when deciding to reconstruct the gastrointestinal tract, with the focus being on colonic anastomoses as high risk and with severe complications. Strategies and recommendations for other intestinal segments (duodenum, jejunum, and ileum) are based on the hemodynamic status and the surgical technique. The duodenum can be managed via primary repair or early duodenal reconstruction. This is consistent with the management of gastroduodenal injuries in our institution. Therefore, we assume that the phrase "less is more" (less surgeries, less reinterventions, fewer procedures) may have full validity in these cases ${ }^{29,30}$. On the other hand, nutritional support plays an essential role in the recovery and management of patients undergoing damage control surgery and should be initiated as early as possible ${ }^{31}$.

The following are recommendations based on the current evidence:

Definitive anastomosis should be performed as soon as possible, a maximum of 24-48 hours after intestinal ligation to avoid septic complications ${ }^{24-28}$.

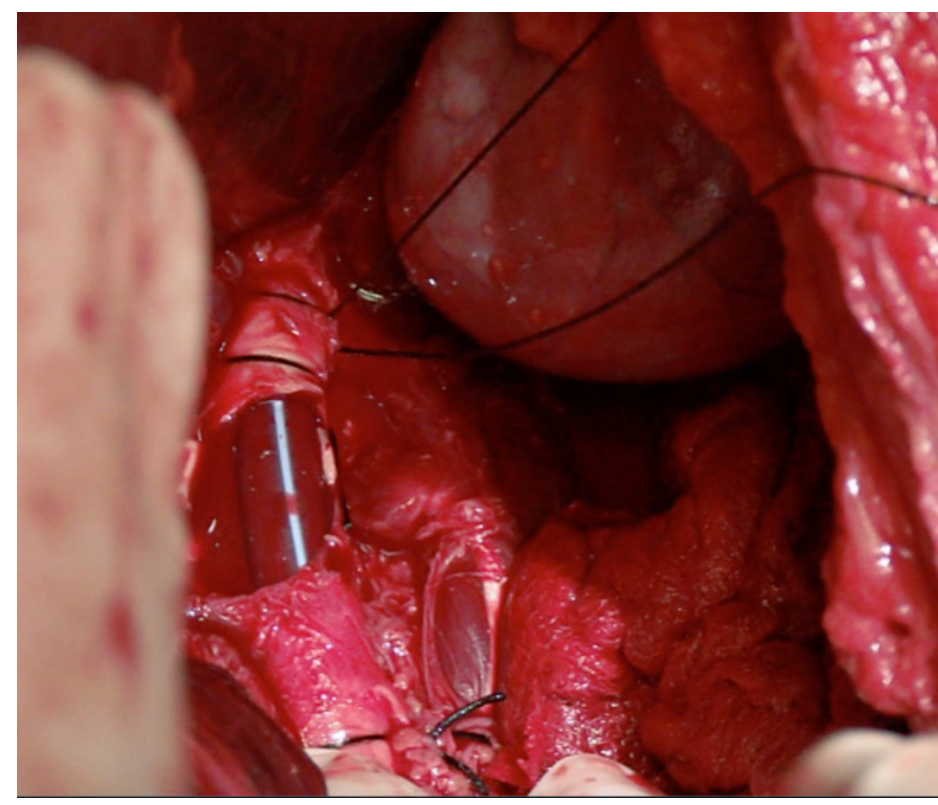

Figure 3. Vascular Shunt on Aorta artery. Infrarenal aorta injury is temporally treated using a vascular shunt 


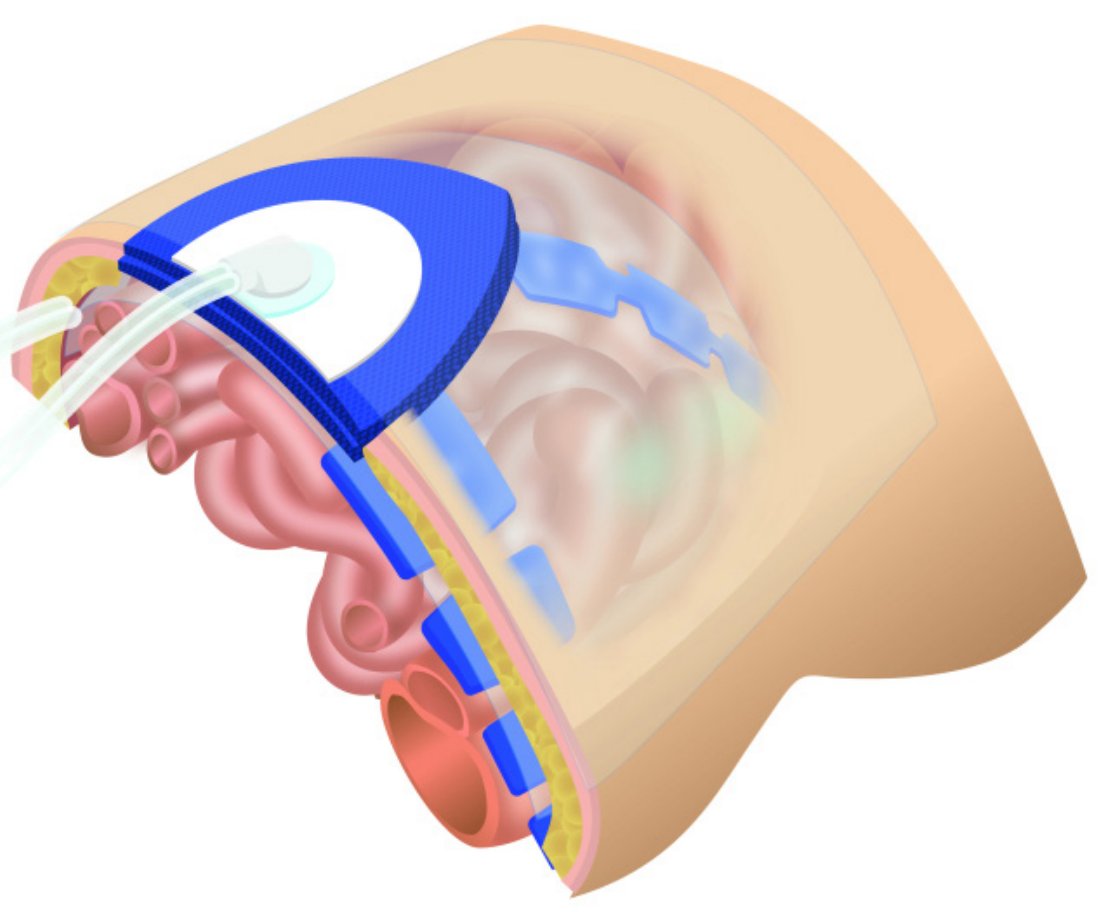

Figure 4. Negative Pressure Wound Therapy to deferred closure of the abdomen. A fenestrated plastic separates intra-abdominal organs, while foam sponges or dressings are placed over it and secured beneath a double layer of adhesive sheets. The suction device is installed over the adhesive film by cutting out a 3 to $3.5 \mathrm{~cm}$ diameter circle

Duodenal reconstruction should be performed during the first 48 hours after the index surgery ${ }^{29,30}$.

Bowel reconstruction can be deferred until the second or third reoperation if the metabolic acidosis, uncontrolled septic focus, or intestinal edema do not persist. On the contrary, the patient is a candidate to perform a diversion. ${ }^{9,26}$.

Total parenteral nutrition is not contraindicated in patients with intestinal ligatures and should be started as early as possible. In cases in which enteral nutrition cannot be established ${ }^{31}$. Enteral nutrition should be initiated once intestinal transit has been re-established and there is no evidence of paralytic ileus ${ }^{31}$.
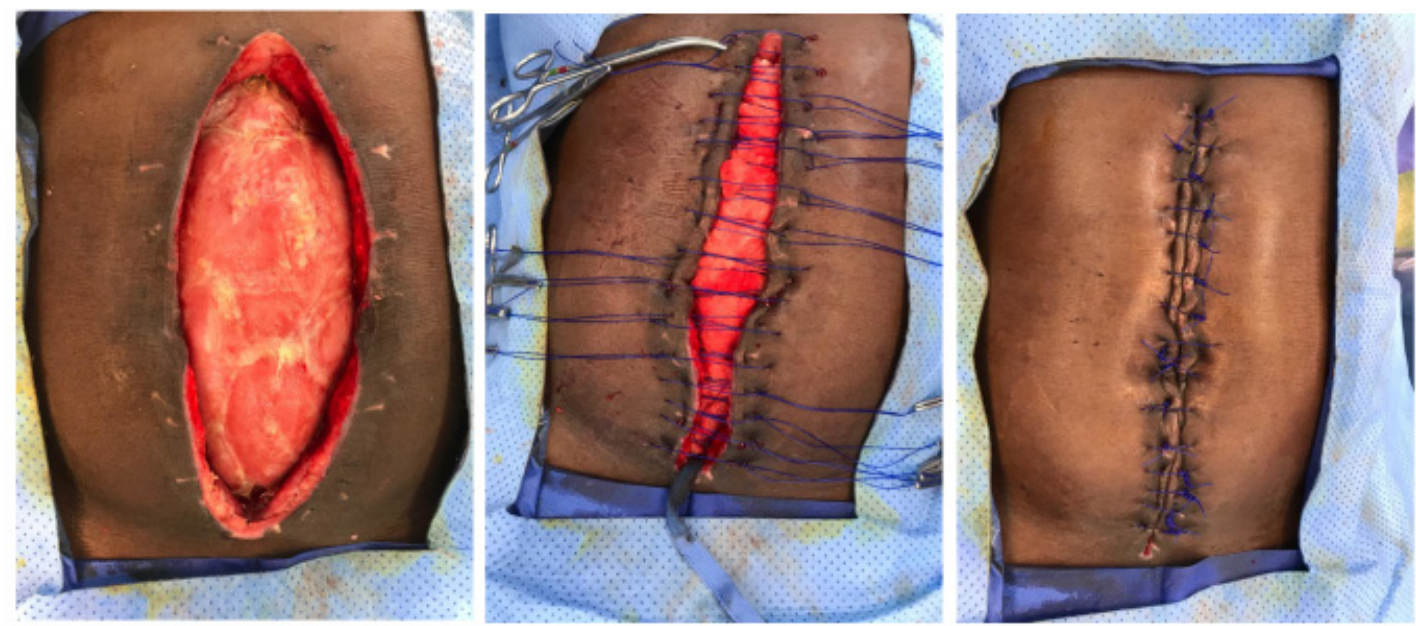

Figure 5. Closure of the abdominal skin. A. Abdominal wall that does not allow closure of fascia and skin. B. The abdomen is closed using 2-0 Prolene interrupted suture of the skin. 


\section{Vascular bypass (Shunt)}

In vascular trauma, the early management of injuries aims to restore the blood flow to the compromised organ or limb. When primary repair is not possible, vascular shunts can be artisanal or commercial, but there is no difference between them and increasing the chance of preserving the function of the affected area. They became popular in military warfare with the rising incidence of peripheral vascular trauma and later on extended to civilian trauma centers where they are currently less frequently used, possibly due to the lack of knowledge and training on their use ${ }^{32}$ (Figure 3).

A shunt's patency depends on several variables, including time, placement technique, the type of vessel involved, and the patient's physiological status. Inaba et al. reported shunt thrombosis in $5.6 \%$ of the cases and most of them were removed in less than 48 hours without developing any complications ${ }^{33}$. Based on animal models, Ding et al. suggested that the ideal time for using a vascular shut is 6 hours to ensure that permeability is preserved ${ }^{34}$. However, in several studies, this time ranges from 2 to 52 hours without the need for anticoagulation.

The evidence conclude that vascular shunts are an appropriate clinical practice in the context of damage control surgery. Vascular shunt must only be used during the first 6 hours after the index surgery because the early definitive management of vascular injury should be a priority.

\section{Abdominal wall closure}

About $10 \%$ to $15 \%$ of laparotomies are managed through damage control surgery resulting in the open abdomen and consequently associated abdominal wall defects, fistula formation, malnutrition, and prolonged stay in the intensive care unit. The question would then be: When is the right time for abdominal wall closure? This is a controversial issue as it depends on many factors: time of re-intervention, number of re-interventions, number of fluids administered during resuscitation, and the temporary closure strategy being used (Figure 3). While it is sometimes impossible to close the abdominal cavity due to bowel loops edema or the patient's hemodynamic status, temporary closure techniques must be employed to avoid bowel dehydration, water and electrolyte disorders, tissue inflammation, and the most feared loss of abdominal wall dominance due to myofascial retraction and tension of abdominal components, all of which will technically hinder future reconstruction ${ }^{35}$. Therefore, closure should be performed as soon as possible once the patient is fully resuscitated, with no further procedures required and no risk of abdominal compartment syndrome. Some authors have considered that the optimal time for abdominal wall closure is during the first nine days ${ }^{36}$. Miller et al. reported 344 damage control laparotomies, with a primary fascial closure rate of $65 \%$, showing that a fascial closure before 8 days was associated with better clinical outcomes ${ }^{24,37}$. When comparing the outcomes of abdominal wall closure at the first re-intervention versus subsequent re-interventions, some studies have shown a lower rate of intra-abdominal abscesses, ventilatory failure, renal failure, and sepsis in early closures. When these variables are adjusted for age, gender, and some trauma scores, it is observed that infectious and non-infectious complications are lower with an early wall closure.

Keeping in mind an early closure of the abdominal wall, we must consider that evisceration is a serious complication, and the use of prophylactic meshes could be a suitable strategy in these patients, balancing the risks and benefits related to their use (surgical site infection, seromas, and prosthesis rejection) ${ }^{38}$. Some consensus recommendations include the use of strategies such as negative pressure therapies or dynamic fascial traction to prevent tissue retraction. In cases of large defects, techniques such as separation of abdominal wall components should not be ruled out (Figure 4). However, excessive efforts to close the abdominal wall could have unfortunate consequences, and planned eventration is an acceptable strategy in this group, which is ideally recommended after 6 months ${ }^{39}$. 
Our recommendation is to perform definitive closure of the abdomen in the second or third reoperation with a maximum time of five or seven days after the index surgery. If the definitive closure of the abdomen does not include fascial or skin, only the skin should be closed to avoid abdominal wall complications (Figure 5).

\section{Conclusion}

Reintervention is just as important as index damage control surgery. Strategies implement to limit the initial damage may fail or have complications if reintervention is not defined on time. This variable is critical to the success of damage control surgery.

\section{References}

1. Rotondo MF, Schwab CW, McGonigal MD, Phillips GR, Fruchterman TM, Kauder DR, et al. "Damage control": an approach for improved survival in exsanguinating penetrating abdominal injury. J Trauma. 1993; 35: 375-82; discussion 382-3.

2. Stone HH, Strom PR, Mullins RJ. Management of the major coagulopathy with onset during laparotomy. Ann Surg. 1983; 197: 532-5. Doi: 10.1097/00000658-198305000-00005.

3. Beldowicz BC. The evolution of damage control in concept and practice. Clin Colon Rectal Surg 2018;31:30-5. Doi: 10.1055/s-0037-1602177.

4. Keel M, Trentz O. Pathophysiology of polytrauma. Injury. 2005; 36: 691-709. Doi: 10.1016/j.injury.2004.12.037.

5. Ditzel RM, Anderson JL, Eisenhart WJ, Rankin CJ, DeFeo DR, Oak S, et al. A review of transfusion- And trauma-induced hypocalcemia: Is it time to change the lethal triad to the lethal diamond? J Trauma Acute Care Surg. 2020; 88: 434-9. Doi: 10.1097/TA.0000000000002570.

6. Roberts DJ, Bobrovitz N, Zygun DA, Ball CG, Kirkpatrick AW, Faris PD, et al. Indications for use of damage control surgery in civilian trauma patients. A content analysis and expert appropriateness rating study. Ann Surg. 2016; 263 : 1018-27. Doi: 10.1097/SLA.0000000000001347.

7. Ordoñez C, Pino L, Badiel M, Sanchez A, Loaiza J, Ramirez O, et al. The 1-2-3 approach to abdominal packing. World J Surg. 2012; 36: 2761-6. Doi: 10.1007/s00268-012-1745-3.

8. Cullinane DC, Jawa RS, Como JJ, Moore AE, Morris DS, Cheriyan J, et al. management of penetrating intraperitoneal colon injuries: A meta-analysis and practice management guideline from the Eastern Association for the Surgery of Trauma. J Trauma Acute Care Surg. 2019;86:505-15. Doi: 10.1097/TA.0000000000002146.

9. Anjaria DJ, Ullmann TM, Lavery R, Livingston DH. Management of colonic injuries in the setting of damage-control laparotomy: One shot to get it right. J Trauma Acute Care Surg. 2014;76:594-600. Doi: 10.1097/TA.0000000000000132.

10. Hirshberg A, Mattox KL. Planned reoperation for severe trauma. Ann Surg. 1995;222:3-8. Doi: 10.1097/00000658$199507000-00002$.

11. Ordoñez CA, Pino LF, Badiel M, Sánchez Al, Loaiza J, Ballestas L, et al. Safety of performing a delayed anastomosis during damage control laparotomy in patients with destructive colon injuries. J. Trauma. 2011; 71: 1512-8. Doi: 10.1097/TA.0b013e31823d0691.

12. Aydin U, Yazici P, Zeytunlu M, Coker A. Is it more dangerous to perform inadequate packing? World J Emerg Surg. 2008;3:1. Doi: 10.1186/1749-7922-3-1.

13. Nicol AJ, Hommes M, Primrose R, Navsaria PH, Krige JEJ. Packing for control of hemorrhage in major liver trauma. World J Surg. 2007;31:569-74. Doi: 10.1007/s00268-006-0070-0. 
14. Kang BH, Jung K, Choi D, Kwon J. Early re-laparotomy for patients with high-grade liver injury after damage-control surgery and perihepatic packing. Surg Today. 2021; 51(6): 891-896. Doi: 10.1007/s00595-02002178-1.

15. Hirshberg A, Wall MJJ, Mattox KL. Planned reoperation for trauma: a two year experience with 124 consecutive patients. J Trauma. 1994;37:365-9.

16. Urschel JD, Bertsch DJ, Takita H. Thoracic packing for postoperative hemorrhage. J Cardiovasc Surg (Torino). 1997;38:673-5.

17. Péterffy Å, Henze A. Haemorrhagic complications during pulmonary resection a retrospective review of 1428 resections with 113 haemorrhagic episodes. Scand Cardiovasc J. 1983;17:283-7. Doi: $10.3109 / 14017438309099366$.

18. Furnary AP, Magovern JA, Simpson KA, Magovern GJ. Prolonged open sternotomy and delayed sternal closure after cardiac operations. Ann Thorac Surg. 1992;54:233-9. Doi: 10.1016/0003-4975(92)91375-J.

19. Manzano-Nunez R, Chica J, Gómez A, Naranjo MP, Chaves H, Muñoz LE, et al. The tenets of intrathoracic packing during damage control thoracic surgery for trauma patients: a systematic review. Eur J Trauma Emerg Surg. 2021; 47(2): 423-434. Doi: 10.1007/s00068-020-01428-8.

20. Moriwaki Y, Toyoda H, Harunari N, Iwashita M, Kosuge T, Arata S, et al. Gauze packing as damage control for uncontrollable haemorrhage in severe thoracic trauma. Ann R Coll Surg Engl. 2013;95:20-5. Doi: 10.1308/00 3588413X13511609956057.

21. Garcia AF, Manzano-Nunez R, Bayona JG, Millan M, Puyana JC. A clinical series of packing the wound tract for arresting traumatic hemorrhage from injuries of the lung parenchyma as a feasible damage control technique. World J Emerg Surg. 2019; 28; 14: 52. Doi: 10.1186/s13017-019-0273-y.

22. Filiberto DM, Fox AD. Preperitoneal pelvic packing: Technique and outcomes. Int J Surg. 2016;33:222-4. Doi: 10.1016/j.jijsu.2016.05.072.

23. Coccolini F, Stahel PF, Montori G, Biffl W, Horer TM, Catena F, et al. Pelvic trauma: WSES classification and guidelines. World J Emerg Surg. 2017;12:1-18. Doi: 10.1186/s13017-017-0117-6.

24. Weinberg JA, Griffin RL, Vandromme MJ, Melton SM, George RL, Reiff DA, et al. Management of colon wounds in the setting of damage control laparotomy: A cautionary tale. J Trauma. 2009; 67: 929-33. Doi: 10.1097/TA.0b013e3181991ab0.

25. Demetriades D, Murray JA, Chan L, Ordoñez C, Bowley D, Nagy KK, et al. Penetrating colon injuries requiring resection: Diversion or primary anastomosis? An AAST prospective multicenter study. J Trauma. 2001; 50: 765-75. Doi: 10.1097/00005373-200105000-00001.

26. Tatebe LC, Jennings A, Tatebe K, Handy A, Prajapati P, Smith M, et al. Traumatic colon injury in damage control laparotomy - A multicenter trial: Is it safe to do a delayed anastomosis? J. Trauma Acute Care Surg. 2017; 82: 742-9. Doi: 10.1097/TA.0000000000001349.

27. Miller PR, Chang MC, Hoth JJ, Holmes IV JH, Meredith JW. Colonic resection in the setting of damage control laparotomy: Is delayed anastomosis safe? Am Surg. 2007;73:606-9. Doi: 10.1177/000313480707300613.

28. Ordoñez CA, Parra M, Caicedo Y, Padilla N, Angamarca E, Serna JJ, et al. Damage control surgical management of combined small and large bowel injuries in penetrating trauma: Are ostomies still pertinent? Colomb Med (Cali). 2021; 52(2): e4114425. Doi: 10.25100/cm.v52i2.4425. 
29. Ordoñez C, García A, Parra MW, Scavo D, Pino LF, Millán M, et al. Complex penetrating duodenal injuries: Less is better. J Trauma Acute Care Surg. 2014;76:1177-83. Doi: 10.1097/TA.0000000000000214.

30. Ordoñez CA, Parra M, Millan M, Caicedo Y, Padilla N, Garcia A, et al. Damage control in penetrating duodenal trauma: less is better. Colomb Med (Cali) 2021; 52(2): e4104509. Doi: 10.25100/cm.v52i2.4509.

31. Fabian TC, Croce MA, Minard G, Bee TK, Cagiannos C, Miller PR, et al. Current issues in trauma. Curr Probl Surg. 2002; 39:1160-244. Doi: 10.1067/msg.2002.128499.

32. Rasmussen TE, Dubose JJ, Asensio JA, Feliciano D V., Fox CJ, Nuñez TC, et al. Tourniquets, vascular shunts, and endovascular technologies: Esoteric or essential? A report from the 2011 AAST Military Liaison Panel. J Trauma Acute Care Surg. 2012;73:282-5. Doi: 10.1097/TA.0b013e3182569df4.

33. Inaba K, Aksoy H, Seamon MJ, Marks JA, Duchesne J, Schroll R, et al. Multicenter evaluation of temporary intravascular shunt use in vascular trauma. J Trauma Acute Care Surg. 2016;80:359-65. Doi: 10.1097/ TA.0000000000000949.

34. Ding W, Wu X, Meng Q, Yan M, Fan X, Ji W, et al. Time course study on the use of temporary intravascular shunts as a damage control adjunct in a superior mesenteric artery injury model. J Trauma. 2010; 68: 409-14. Doi: 10.1097/TA.0b013e31819ea416.

35. Demetriades D, Salim A. Management of the Open Abdomen. Surg Clin North Am. 2014;94:131-53. Doi: 10.1016/j.suc.2013.10.010.

36. Coccolini F, Roberts D, Ansaloni L, Ivatury R, Gamberini E, Kluger Y, et al. The open abdomen in trauma and non-trauma patients: WSES guidelines. World J Emerg Surg. 2018; 13: 7. Doi: 10.1186/s13017-018-0167-4.

37. Miller RS, Morris JA, Diaz JJ, Herring MB, May AK, Rotondo MF, et al. Complications after 344 damage-control open celiotomies. J Trauma. 2005; 59: 1365-74. Doi: 10.1097/01.ta.0000196004.49422.af.

38. Lima HVG, Rasslan R, Novo FCF, Lima TMA, Damous SHB, Bernini CO, et al. Prevention of fascial dehiscence with onlay prophylactic mesh in emergency laparotomy: a randomized clinical trial. J Am Coll Surg. 2020; 230: 76-87. Doi: 10.1016/j.jamcollsurg.2019.09.010.

39. Godat L, Kobayashi L, Costantini T, Coimbra R. Abdominal damage control surgery and reconstruction: World society of emergency surgery position paper. World J Emerg Surg. 2013; 8: 53. Doi: 10.1186/1749-7922-8-53. 